\title{
Electromagnetic-Thermal Integrated Design Optimization for Hypersonic Vehicle Short-Time Duty PM Brushless DC Motor
}

\author{
Quanwu Li, Manfeng Dou, Bo Tan, Haitao Zhang, and Dongdong Zhao \\ School of Automation, Northwestern Polytechnical University, Xian 710072, China \\ Correspondence should be addressed to Dongdong Zhao; zhaodong@nwpu.edu.cn
}

Received 30 May 2016; Accepted 30 August 2016

Academic Editor: Linda L. Vahala

Copyright ( 2016 Quanwu Li et al. This is an open access article distributed under the Creative Commons Attribution License, which permits unrestricted use, distribution, and reproduction in any medium, provided the original work is properly cited.

\begin{abstract}
High reliability is required for the permanent magnet brushless DC motor (PM-BLDCM) in an electrical pump of hypersonic vehicle. The PM-BLDCM is a short-time duty motor with high-power-density. Since thermal equilibrium is not reached for the PM-BLDCM, the temperature distribution is not uniform and there is a risk of local overheating. The winding is a main heat source and its insulation is thermally sensitive, so reducing the winding temperature rise is the key to the improvement of the reliability. In order to reduce the winding temperature rise, an electromagnetic-thermal integrated design optimization method is proposed. The method is based on electromagnetic analysis and thermal transient analysis. The requirements and constraints of electromagnetic and thermal design are considered in this method. The split ratio and the maximum flux density in stator lamination, which are highly relevant to the windings temperature rise, are optimized analytically. The analytical results are verified by finite element analysis (FEA) and experiments. The maximum error between the analytical and the FEA results is $4 \%$. The errors between the analytical and measured windings temperature rise are less than $8 \%$. It can be proved that the method can obtain the optimal design accurately to reduce the winding temperature rise.
\end{abstract}

\section{Introduction}

There are many kinds of permanent magnet brushless DC motor (PM-BLDCM) in the engine of hypersonic vehicle to achieve fast, flexible, and precise thrust control [1-5]. These PM-BLDCMs have different load profiles, which can be classified by the standard of IEC 60034-1:2010 as ten kinds of duty types: S1 to S10 [6]. The short-time duty (S2) PMBLDCM in hypersonic vehicle can be used in pumps, actuators, fans, and so on. Reliability and power-density are the fundamental requirements for the hypersonic vehicle PMBLDCM [7-9]. Thermal equilibrium is not reached for shorttime duty PM-BLDCM, so there is a risk of local overheating $[10,11]$. Overheat can cause damage to those components which are sensitive to the temperature, especially, the winding insulation. As the temperature increases, the winding insulation lifetime is heavily reduced by the thermal-aging degradation effect [12-14]. Reliability of the short-time duty PM-BLDCM is directly affected by the winding temperature rise. Therefore, reducing the winding temperature rise is the key to the improvement of the PM-BLDCM's reliability [15].
Both the electromagnetic and thermal designs need to be concerned for the PM-BLDCM. The electromagnetic and thermal design parameters are coupled. The electromagneticthermal integrated design needs to be adopted to reduce the winding temperature rise. There are different types of electromagnetic-thermal integrated design methods proposed in the literatures. Nevertheless, these methods can be divided into two main categories: numerical methods and analytical methods $[12,15-21]$. The two methods have their own advantages and disadvantages. There are also some approaches which combine the two methods [16, 17]. The numerical methods, which are based on the finite element analyses (FEA) and computational fluid dynamics (CFD), can get the accurate results intuitively. However, the numerical methods have high requirements in terms of model setup and computational time $[19,20]$. The analytical methods, which are based on the electromagnetic and thermal parametric model, provide a fast and accurate solution for the electromagnetic-thermal integrated design optimization $[20,21]$. In preceding publications, the electromagneticthermal integrated design optimization is based on the 
thermal steady state. However, the winding temperature is directly affected by the thermal transients for the shorttime duty PM-BLDCM. Therefore, in this paper, an analytical electromagnetic-thermal integrated design optimization method, which is based on the thermal transients, is studied for the short-time duty PM-BLDCM.

Some main design parameters are highly relevant to the electromagnetic and thermal performance, such as the stator outer diameter $D_{o}$, the stator inner diameter $D_{s}$, and the motor active axial length $l_{\text {ef }}[16-21]$. The winding temperature rise can be decreased by optimizing the parameters. In some existing papers, there are too many variables involved and the optimization is complex $[15,19-21]$. According to motor design theory, the main design parameters are determined by the electric load and magnetic load, which can be converted to the maximum flux density in the stator lamination $B_{m}$, the stator inner diameter $D_{s}$, and copper loss $P_{\mathrm{Cu}}$ [22]. When two of $B_{m}, D_{s}$, and $P_{\mathrm{Cu}}$ are determined, the dimensions of the PM-BLDCM can be obtained. For low-speed PM-BLDCM, the copper loss is the only main loss, and so $D_{s}$ and $P_{\mathrm{Cu}}$ are usually chosen to optimize [23-28]. For the high-powerdensity PM-BLDCM with high-speed, $B_{m}$ and $D_{s}$ are suitable for the optimization. In order to make data comparable, $D_{s}$ is usually expressed as split ratio, which is the ratio of the stator inner diameter $D_{s}$ to the outer diameter $D_{o}$. In this paper, the electromagnetic and thermal parameters are converted to the functions of the split ratio and $B_{m}$. Only two variables are involved, so the optimization can be highly simplified.

The split ratio is an important design parameter since it has a significant influence on temperature rise, torque, loss, efficiency, and cost [23-27]. There are many investigations on the optimization of the split ratio in some existing papers. Different split ratio optimization methods for electrically excited motors, surface mounted PM motors, interior PM motors, external rotor PM motors, and so forth are presented in [23-25]. These methods are aimed at low-speed motor and thermal limitation is achieved by limiting the copper loss. In [26], Tang et al. indicate that the split ratio has a significant influence on temperature rise of the short-time duty PM-BLDCM. In [27], Reichert et al. indicate that the local thermal situations should be considered, especially for the stator winding, which is one of the main heat sources; an analytical split ratio optimization method for low-speed PM-BLDCM is developed with global and local thermal limitations. In [23-27], the split ratio has been optimized for these PM-BLDCMs whose losses are dominated by the copper loss, whereas other losses can be neglected. Speed has a significant influence on the optimal split ratios [28]. For the high-power-density PM-BLDCM in this paper, the iron loss, the rotor eddy current loss, the rotor air friction loss, and the mechanical friction loss should be considered in the design optimization.

In this paper, an electromagnetic-thermal integrated design optimization method is proposed to reduce the winding temperature rise of the short-time duty PM-BLDCM. The analytical design model and electromagnetic torque equation are given in Section 2. The losses are calculated in Section 3. The thermal transient analysis and the optimal design determination method are presented in Section 4.

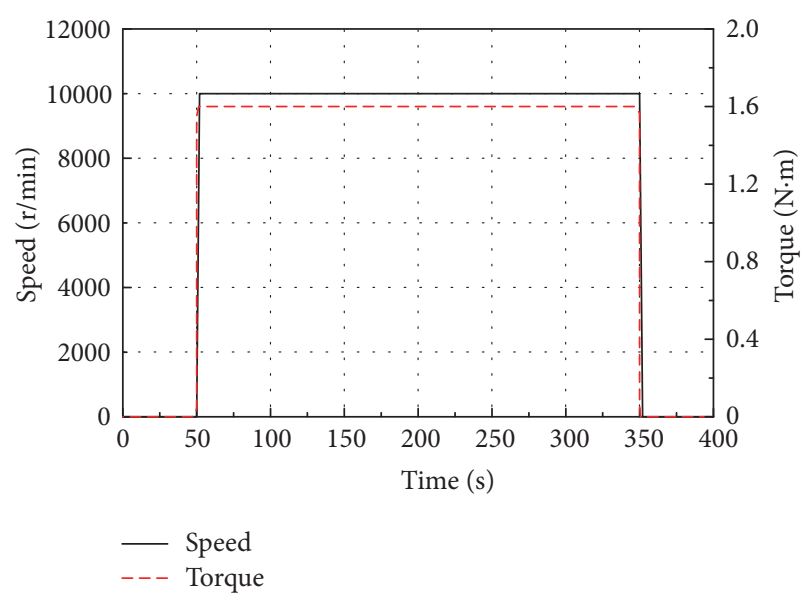

FIGURE 1: Load profile of the PM-BLDCM.

Finally, the analytical optimization results are verified by FEA and experiments.

\section{Electromagnetic Torque Calculation}

The PM-BLDCM intended to design is used in an electrical pump of hypersonic vehicle. High reliability and high-powerdensity are required. The PM-BLDCM operates for a short time in a flight. Some constraints for the PM-BLDCM are given as follows:

(1) The motor is required to be able to operate $300 \mathrm{~s}$ per cycle with full load. The load profile is shown in Figure 1.

(2) The rotational speed and torque under full load condition are $10000 \mathrm{r} / \mathrm{min}$ and $1.6 \mathrm{~N} \cdot \mathrm{m}$, respectively.

(3) Outer diameter and length of the motor are limited.

(4) The operating altitude is $20 \mathrm{~km}$.

(5) The motor is cooled by natural cooling.

(6) The maximum ambient temperature is $80^{\circ} \mathrm{C}$.

The operation time of the PM-BLDCM is far less than the time deenergized and at rest. There is enough time for it to reestablish motor temperatures within $2^{\circ} \mathrm{C}$ of the coolant temperature [6]. Therefore, the PM-BLDCM is a short-time duty motor.

Air density at altitude of $20 \mathrm{~km}$ is $0.0889 \mathrm{~kg} / \mathrm{m}^{3}$, which is $1 / 14$ that of $0 \mathrm{~km}$. At high altitudes, due to the thin air, the convection cooling capacity is reduced.

Some designs of the PM-BLDCM prototype, such as $120^{\circ}$ electrical conduction, inner rotor, surface mounted magnets, air-gap width, slots number, poles number, outer stator diameter, and axial length, have been designed previously before optimization. Some requirements and design parameters are shown in Table 1.

The configuration and main geometric parameters of the PM-BLDCM are shown in Figure 2, where $b_{t}$ is the stator tooth width; $b_{j}$ is the stator back iron width; $h_{t}$ is the tooth-tip 
TABLE 1: Main parameters of the prototype motor.

\begin{tabular}{lc}
\hline Items & Values \\
\hline Rated speed $(\mathrm{r} / \mathrm{min})$ & 10000 \\
Outer stator diameter $(\mathrm{mm})$ & 80 \\
Poles number & 4 \\
Rated torque $(\mathrm{N} \cdot \mathrm{m})$ & 1.6 \\
Active axial length $(\mathrm{mm})$ & 30 \\
Slots number & 12 \\
\hline
\end{tabular}

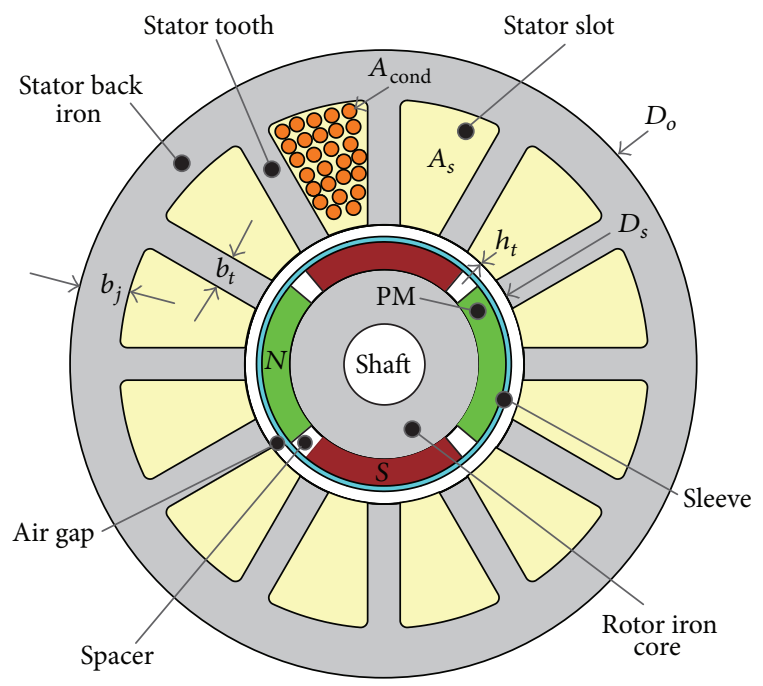

FIgURE 2: Configuration and geometric parameters of the PMBLDCM.

height; $D_{o}$ and $D_{s}$ are the outer diameter and inner diameter of the stator core, respectively; $A_{s}$ is the stator slot area.

The split ratio is given as

$$
\lambda=\frac{D_{s}}{D_{o}} .
$$

The stator tooth width $b_{t}$ and the stator back iron width $b_{j}$ can be expressed as

$$
\begin{aligned}
& b_{t}=\frac{\pi D_{o} \lambda B_{\delta}}{Q B_{m}}, \\
& b_{j}=\frac{\pi D_{o} \lambda B_{\delta}}{4 p B_{m}},
\end{aligned}
$$

where $B_{\delta}$ is the air-gap flux density, which is nearly a constant for surface mounted PM motors [24]; $Q$ is the stator slots number; $p$ is the poles number.

According to the geometric relationships and the expressions of $b_{t}$ and $b_{j}$, the slot area can be obtained as

$$
A_{s}=\frac{\pi D_{o}^{2}}{4 Q} F\left(\lambda, B_{m}\right) \text {, }
$$

where $F\left(\lambda, B_{m}\right)$ is a function of $\lambda$ and $B_{m}$, shown as

$$
\begin{gathered}
F\left(\lambda, B_{m}\right)=\left\{\left[\frac{\pi}{2 p}\left(\frac{\pi}{2 p}+2\right) \frac{B_{\delta}^{2}}{B_{m}^{2}}+\frac{2 B_{\delta}}{B_{m}}-1\right] \lambda^{2}\right. \\
\left.-2\left[\left(\frac{\pi}{2 p}+1-\varepsilon\right) \frac{B_{\delta}}{B_{m}}+\varepsilon\right] \lambda+1-\varepsilon^{2}\right\},
\end{gathered}
$$

where $\varepsilon$ is the ratio of $2 h_{t}$ and $D_{o}$ :

$$
\varepsilon=\frac{2 h_{t}}{D_{o}} .
$$

The cross-sectional area of a conductor is given as

$$
A_{\text {cond }}=\frac{\pi A_{s} k_{s} Q}{24 W_{\Phi}}
$$

where $k_{s}$ is the slot fill factor; $W_{\Phi}$ is the number of turns each phase.

The back-EMF of a single conductor is given as

$$
e_{1}=0.5 B_{\delta} l_{\mathrm{ef}} D_{s} \omega_{r}
$$

where $\omega_{r}$ is the angular velocity of the rotor; $l_{\mathrm{ef}}$ is the active motor axial length.

The phase back-EMF can be obtained as

$$
E_{\mathrm{ph}}=2 W_{\Phi} e_{1} k_{N}=B_{\delta} l_{\mathrm{ef}} D_{s} W_{\Phi} k_{N} \omega_{r},
$$

where $k_{N}$ is the winding factor.

The electromagnetic torque is given as

$$
T_{\mathrm{em}}=\frac{2 E_{\mathrm{ph}} I_{a}}{\omega_{r}}=2 B_{\delta} l_{\mathrm{ef}} D_{s} W_{\Phi} k_{N} I_{a},
$$

where $I_{a}$ is the winding current.

\section{Loss Calculation}

Losses are the heat source that causes increase of motor temperature. Losses of the high-power-density PM-BLDCM mainly include the copper loss, the iron loss, the rotor eddy current loss, the mechanical friction loss, and the rotor air friction loss [29].

3.1. Copper Loss. When the winding temperature of the PMBLDCM is ambient temperature $\tau_{0}$, the winding temperature rise is 0 , and the copper loss can be expressed as

$$
P_{\mathrm{Cu} 0}=2 I_{a}^{2} R_{a}=2 I_{a}^{2} \rho_{\mathrm{Cu}} \frac{2 W_{\Phi}\left(l_{\mathrm{ef}}+l_{\mathrm{ed}}\right)}{A_{\text {cond }}},
$$

where $\rho_{\mathrm{Cu}}$ is the resistivity of copper at ambient temperature $\tau_{0} ; R_{a}$ is the winding phase resistance; $l_{\mathrm{ed}}$ is the average endwinding length, which is given as

$$
l_{\mathrm{ed}}=\frac{\pi^{2} D_{o} y_{1}}{4 Q}\left(1-\frac{\pi \lambda B_{\delta}}{2 p B_{m}}+\lambda+\varepsilon\right),
$$

where $y_{1}$ is winding pitch. 
According to (3)-(10), the copper loss expression in (10) can be rewritten as

$$
P_{\mathrm{Cu} 0}=\frac{C_{1} T_{\mathrm{em}}^{2}\left(l_{\mathrm{ef}}+l_{\mathrm{ed}}\right)}{\lambda^{2} F\left(\lambda, B_{m}\right)}
$$

with the constant $C_{1}$ :

$$
C_{1}=\frac{96 \rho_{\mathrm{Cu}}}{\pi^{2} B_{\delta}^{2} l_{\mathrm{ef}}^{2} k_{s} k_{N}^{2} D_{o}^{4}}
$$

3.2. Iron Loss. The iron loss in the stator lamination is given as

$$
P_{\mathrm{Fe}}=P_{t}\left(G_{j}+G_{t}\right)
$$

where $P_{t}$ is the iron loss per unit mass $(\mathrm{kg}) ; G_{j}$ is the mass of the stator back iron; $G_{t}$ is the mass of the stator teeth.

$P_{t}$ is separated into the hysteretic loss component $P_{h}$, the classical eddy current loss component $P_{c}$, and the excess eddy current losses component $P_{e}$, and $P_{t}$ can be expressed as [30]

$$
P_{t}=P_{h}+P_{c}+P_{e}=k_{h} f B_{m}^{\alpha}+k_{c} f^{2} B_{m}^{2}+k_{e} f^{1.5} B_{m}^{1.5},
$$

where $k_{h}$ and $\alpha$ are the hysteretic loss constants; $k_{c}$ is the classical eddy current loss constant; $k_{e}$ is the excess eddy current losses constant; $f$ is the frequency.

Based on the analytical design model, the expressions of $G_{j}$ and $G_{t}$ can be obtained as

$$
\begin{aligned}
G_{j} & =\pi \sigma_{\mathrm{Fe}} l_{\mathrm{ef}} D_{o}^{2} B_{\delta}\left(\frac{\pi \lambda}{4 p B_{m}}-\frac{\pi^{2} B_{\delta} \lambda^{2}}{16 p^{2} B_{m}^{2}}\right), \\
G_{t} & =\pi \sigma_{\mathrm{Fe}} l_{\mathrm{ef}} D_{o}^{2} B_{\delta}\left[\frac{\lambda}{2 B_{m}}-\left(\frac{1}{2 B_{m}}+\frac{\pi B_{\delta}}{4 p B_{m}^{2}}\right) \lambda^{2}\right],
\end{aligned}
$$

where $\sigma_{\mathrm{Fe}}$ is the density of the stator lamination material.

3.3. Rotor Eddy Current Loss. Eddy current loss in the permanent magnets, the sleeve, and the rotor yoke is caused by the space MMF harmonics and time MMF harmonics. The eddy current loss mainly locates in the permanent magnets and the sleeve, and the loss in the rotor yoke can be ignored [31]. The rotor eddy current loss can be calculated by [32]

$$
P_{\text {eddy }}=2 p \frac{\omega_{r}}{2 \pi} \int_{0}^{2 \pi / \omega_{r}} \int_{R_{i}}^{R_{o}} \int_{-\alpha_{p} / 2}^{\alpha_{p} / 2} \rho J_{m}^{2} r d r d \theta d t
$$

where $R_{o}$ is outer diameter of sleeve or magnets; $R_{i}$ is inner diameter of sleeve or magnets; $\alpha_{p}$ is the pole arc for magnets, and the value is $\pi / p$ for sleeve; $\rho$ is electrical conductivity of sleeve or magnets; $J_{m}$ is the current density in the sleeve or magnets.

3.4. Mechanical Friction Loss. The mechanical friction loss is caused by running of the bearing, and its expression can be expressed as [33]

$$
P_{\text {mech }}=f_{0}\left(\frac{30 v_{\mathrm{kv}}}{\pi}\right)^{2 / 3} d_{m}^{3} \omega_{r}^{5 / 3}+f_{1} H_{1}^{a} d_{m}^{b} \omega_{r}
$$

where $f_{0}$ is the coefficient determined by the type and lubrication of the bearing; $v_{\mathrm{kv}}$ is the kinematic viscosity of the lubricating oil; $d_{m}$ is the average diameter of the bearing; $f_{1}$ is the coefficient determined by the type and load of bearing; $H_{1}$ is the dynamic load of the bearing; $a$ and $b$ are the coefficients depending on the type and load of the bearing.

3.5. Rotor Air Friction Loss. The rotor air friction loss is generated by the friction between rotor and air. According to [34], the rotor air friction loss can be obtained as

$$
P_{\mathrm{air}}=k_{\mathrm{rc}} C_{f} \pi \rho_{\mathrm{air}} \omega_{r}^{3} r^{4} l_{\mathrm{ef}},
$$

where $k_{\mathrm{rc}}$ is the rotor surface roughness coefficient, and its value is 1 for smooth rotor surfaces; $\rho_{\text {air }}$ is air density; $C_{f}$ is air friction coefficient, and it can be expressed as

$$
C_{f}=\frac{0.0152}{R_{e \delta}{ }^{0.24}}
$$

with the Couette Reynolds number being

$$
R_{e \delta}=\frac{\rho_{\mathrm{air}} \omega_{r} r \delta}{\mu_{\mathrm{air}}}
$$

where $\delta$ is the air-gap width.

The rotor air friction loss is close related to the radius of the rotor $r$, which can be expressed as a function of $\lambda: r=$ $\left(D_{o} \cdot \lambda\right) / 2-\delta$.

\section{Determination of the Optimal Design}

In various components of the PM-BLDCM, the winding and permanent magnet are the main heat sources and their reliabilities are sensitive to temperature. In order to increase the reliability of the PM-BLDCM, high temperature materials are adopted besides decreasing the motor temperature. The grade of the enamel insulated wires intended to adopt is $Q Y$ $2 / 220$ and its maximum operating temperature is $220^{\circ} \mathrm{C}$. The permanent magnet material intended to adopt is $\mathrm{Sm}_{2} \mathrm{Co}_{17}$, and its grade is $X G S 239 / 199 / 350$. The maximum operating temperature of the permanent magnet is $350^{\circ} \mathrm{C}$. Temperature tolerance ability of the magnets is higher than that of winding. In addition, the life of winding decreases with temperature rises. In order to improve the reliability of the PM-BLDCM, the winding temperature needs to be decreased.

The air-gap thermal resistance is larger than other thermal resistances in the stator. Furthermore, the airgap thermal resistance increases with air density decreases. Therefore, the effect of the rotor temperature on the winding temperature can be ignored at the high altitude. The winding temperature rise is mainly determined by the copper and iron losses. The winding temperature rise can be calculated by the following equation:

$$
\Delta \tau_{\mathrm{Cu} . \infty}=\frac{P_{\mathrm{Fe}}+P_{\mathrm{Cu}}}{k_{\alpha} A}+P_{\mathrm{Cu}} R_{\mathrm{CF}},
$$

where $k_{\alpha}$ is the heat transfer coefficient of the PM-BLDCM; $A$ is the cooling area of the PM-BLDCM; $R_{\mathrm{CF}}$ is the thermal resistance between the windings and stator iron core. 
The heat transfer coefficient of the PM-BLDCM is the sum of the natural convection and radiation heat transfer coefficients. The natural convection heat transfer coefficient decreases with altitude rises. In order to improve the cooling capacity of the PM-BLDCM at high altitude, the radiation heat transfer coefficient needs to be raised by increasing the emissivity of the motor surface.

The electromagnetic torque is the sum of the resistance torque and the output torque. The electromagnetic torque can be expressed as

$$
T_{\mathrm{em}}=T_{2}+\frac{\left(P_{\mathrm{Fe}}+P_{0}\right)}{\omega_{r}},
$$

where $T_{2}$ is the output torque; $P_{0}$ is the sum of the rotor eddy current loss, the rotor air friction loss, and the mechanical friction loss, and it is expressed as

$$
P_{0}=P_{\text {eddy }}+P_{\text {air }}+P_{\text {mech }} .
$$

According to (14)-(21), $P_{0}$ can be converted as a function of $\lambda$ and $B_{m}$

Combining (12) and (23), the copper loss at ambient temperature $\tau_{0}$ can be obtained as

$$
P_{\mathrm{Cu} 0}=\frac{C_{1}\left(l_{\mathrm{ef}}+l_{\mathrm{ed}}\right)}{\lambda^{2} F\left(\lambda, B_{m}\right)}\left[T_{2}^{2}+\frac{2 T_{2}\left(P_{\mathrm{Fe}}+P_{0}\right)}{\omega_{r}}\right] .
$$

The copper loss increases with temperature rises. When the winding temperature rise is $\Delta \tau_{\mathrm{Cu}}$, the copper loss is given as

$$
P_{\mathrm{Cu}}=P_{\mathrm{Cu} 0}\left(1+\gamma_{\mathrm{Cu}} \cdot \Delta \tau_{\mathrm{Cu}}\right),
$$

where $\gamma_{\mathrm{Cu}}$ is resistivity temperature coefficient of copper.

Based on (22) and (26), the steady winding temperature rise can be obtained as

$$
\Delta \tau_{\mathrm{Cu} . \infty}=\frac{P_{\mathrm{Fe}}+\left(1+k_{\alpha} A R_{\mathrm{CF}}\right) P_{\mathrm{Cu} 0}}{k_{\alpha} A-\gamma_{\mathrm{Cu}}\left(1+k_{\alpha} A R_{\mathrm{CF}}\right) P_{\mathrm{Cu} 0}} .
$$

The winding transient temperature rise is given as

$$
\Delta \tau_{\mathrm{Cu}}=\Delta \tau_{\mathrm{Cu} . \infty} \cdot\left(1-e^{-t / \Gamma}\right),
$$

where $t$ is time and $\Gamma$ is thermal time constant. Since $t$ is within $0 s-300 s$, the temperature difference between the windings and stator iron core is negligible. It can be assumed that all parts of the stator have the same temperature. Therefore, $\Gamma$ can be obtained as

$$
\Gamma=\frac{c_{p} m}{k_{\alpha} A},
$$

where $c_{p}$ is the average specific heat capacity of the stator; $m$ is the mass of the stator.

The ratio of different losses in total losses and thermal time constant can be changed by adjusting $\lambda$ and $B_{m}$. In other words, the heat source and the rate of temperature rise can be changed by adjusting $\lambda$ and $B_{m}$. The variation of $\Delta \tau_{\mathrm{Cu}}$ with $\lambda$ and $B_{m}$ when $t=300 \mathrm{~s}$ is illustrated in Figure 3. It can be seen that $\Delta \tau_{\mathrm{Cu}}$ can be reduced by optimizing $\lambda$ and $B_{m}$. There

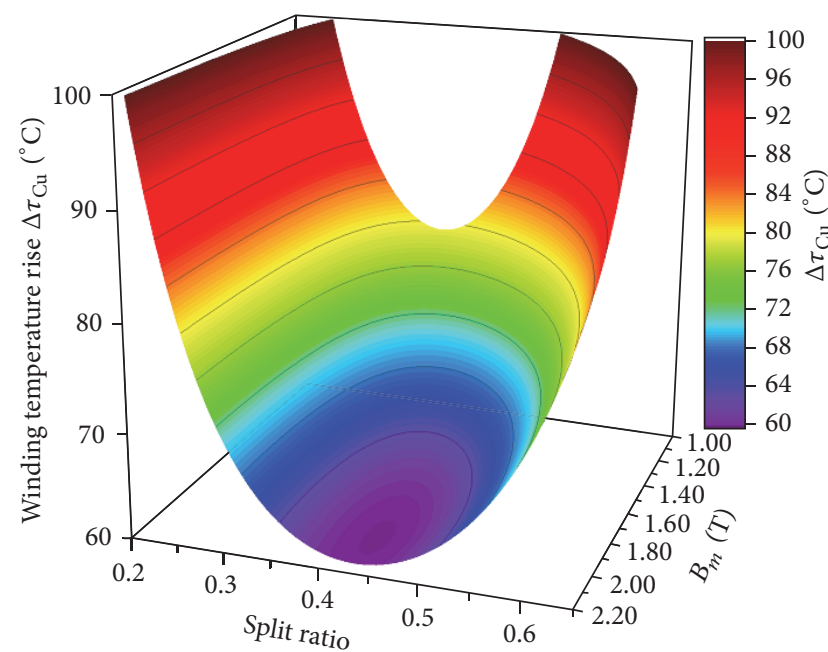

FIGURE 3: Variation of the winding temperature rise with split ratio and $B_{m}$.

is an optimal combination of $\lambda$ and $B_{m}$ to gain the minimum temperature rise. The optimal combination can be obtained by solving the equations group:

$$
\begin{aligned}
& \frac{\partial\left(\Delta \tau_{\mathrm{Cu}}\right)}{\partial \lambda}=0, \\
& \frac{\partial\left(\Delta \tau_{\mathrm{Cu}}\right)}{\partial B_{m}}=0 .
\end{aligned}
$$

Using (30), the optimal $\lambda$ and $B_{m}$ of the PM-BLDCM in this paper are calculated as 0.44 and $2.02 \mathrm{~T}$. However, $2.02 \mathrm{~T}$ of $B_{m}$ is hard to achieve for the stator lamination steel material $D W 310-35$. Figure 3 shows that $B_{m}$ should be close to $2.02 \mathrm{~T}$ to reduce the temperature rise. Considering the magnetic saturation point of the lamination steel of the prototype, $1.7 \mathrm{~T}$ of $B_{m}$ is chosen and the corresponding optimal $\lambda$ is 0.43 .

On the other hand, it should be noted that the optimal $B_{m}$ decreases with speed rises, and the value of $B_{m}$ may be less than the saturation point for some high-speed PM-BLDCM. In this case, the actual value of optimal $B_{m}$ and $\lambda$ should be chosen.

\section{FEA and Experimental Verifications}

The analytical results are verified by FEA and experiments. The verification purpose is to prove that the analytical optimal design is accurate and the optimization method can minimize the winding temperature rise.

In FEA verification, the air density at altitude $20 \mathrm{~km}$ and the ambient temperature of $80^{\circ} \mathrm{C}$ were considered. Different designs, which include the optimal design, are chosen to simulate. As shown in Figure 4, several motor designs with different combinations of $\lambda$ and $B_{m}$ are chosen from the contour. The motor designs of $\mathrm{C} 1, \mathrm{C} 2, \mathrm{C} 3$, and $\mathrm{C} 4$ are designed by employing 0.43 of $\lambda$ for the four specific $B_{m} 1.1 \mathrm{~T}, 1.3 \mathrm{~T}$, $1.5 \mathrm{~T}$, and 1.7 T, respectively. The motor designs of R1, R2, R3, $\mathrm{R} 4$, and $\mathrm{R} 5$ are designed by employing $1.7 \mathrm{~T}$ of $B_{m}$ for the five 


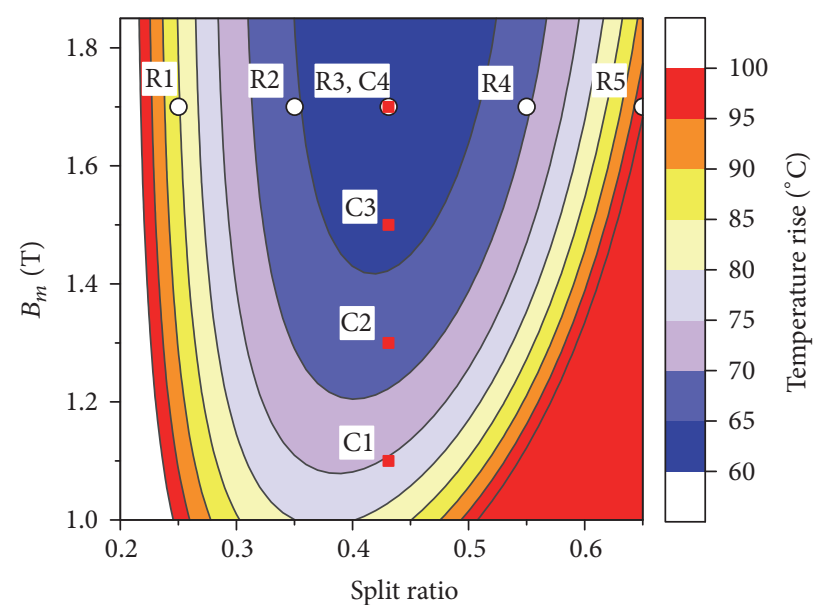

Figure 4: Analytical contour of the winding temperature rise and the points used for FEA verifications.

TABLE 2: Analytical and FEA results of different designs $\left(\Delta \tau_{\mathrm{Cu} . \mathrm{Anl}}\right.$ and $\Delta \tau_{\mathrm{Cu} . \mathrm{FEA}}$ are the analytical and FEA winding temperature rise).

\begin{tabular}{lcccc}
\hline Designs & $\lambda$ & $B_{m}(\mathrm{~T})$ & $\Delta \tau_{\text {Cu.Anl }}\left({ }^{\circ} \mathrm{C}\right)$ & $\Delta \tau_{\text {Cu.FEA }}\left({ }^{\circ} \mathrm{C}\right)$ \\
\hline $\mathrm{C} 1$ & 0.43 & 1.1 & 75.4 & 73.0 \\
$\mathrm{C} 2$ & 0.43 & 1.3 & 67.6 & 66.9 \\
$\mathrm{C} 3$ & 0.43 & 1.5 & 63.8 & 63.0 \\
$\mathrm{C} 4, \mathrm{R} 3$ & 0.43 & 1.7 & 62.0 & 60.6 \\
$\mathrm{R} 1$ & 0.25 & 1.7 & 85.4 & 82.0 \\
$\mathrm{R} 2$ & 0.35 & 1.7 & 65.5 & 63.0 \\
$\mathrm{R} 4$ & 0.55 & 1.7 & 69.5 & 68.3 \\
$\mathrm{R} 5$ & 0.65 & 1.7 & 98.9 & 97.9 \\
\hline
\end{tabular}

specific $\lambda 0.25,0.35,0.43,0.55$, and 0.65 , respectively. Among these designs, C4 (R3) is the optimal design in analytical prediction. Since C4 and R3 are the same design, there are eight designs for the FEA verification in total.

The analytical and FEA predicted winding temperature rises of the different designs are shown in Table 2. The FEA results are compared with analytical results in Figures 5 and 6. The maximum error, minimum error, and average error between analytical results and FEA results are $4.0 \%, 1.0 \%$, and $2.3 \%$. The FEA results agree well with the analytical results. The winding temperature rise of design C4 (R3) is proved to be the smallest. The 3D thermal field of C4 (R3) design at $t=$ $300 \mathrm{~s}$ is shown in Figure 7.

As shown in Figure 8(a), a PM-BLDCM prototype was manufactured according to the design C4 (R3). The prototype is driven by a pulse-width modulation (PWM) inverter. The prototype and its controller are integrated to save the space. Surface of the prototype is painted black to increase the emissivity. Since there is no equipment to simulate the environment at the altitude of $20 \mathrm{~km}$, the prototype was tested on the ground with normal temperature and normal atmospheric pressure, which are $19^{\circ} \mathrm{C}$ and $100.8 \mathrm{kPa}$. The experimental platform is shown in Figure 8(b). Total running time of the prototype is $300 \mathrm{~s}$. In the running status of the prototype, the load torque and the speed were maintained

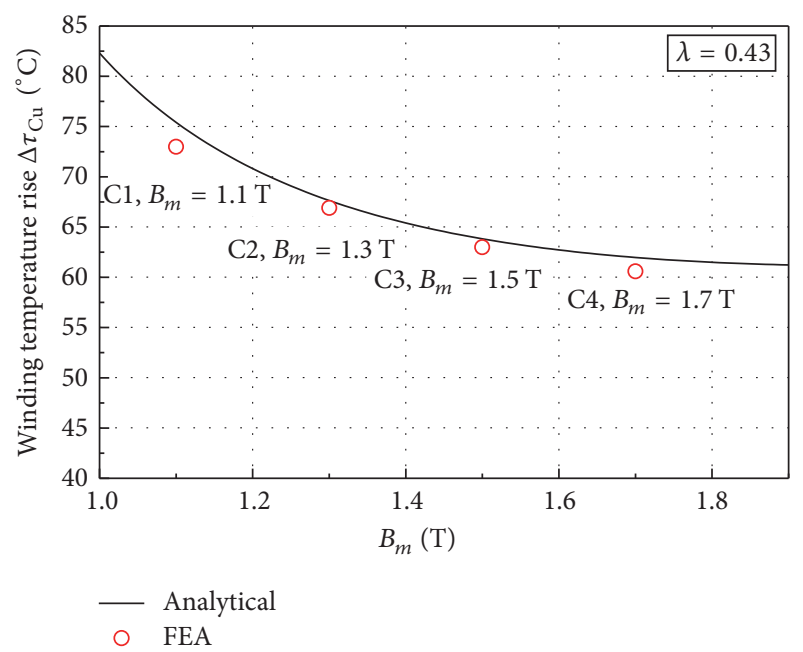

Figure 5: FEA verifications of the designs C1, C2, C3, and C4.

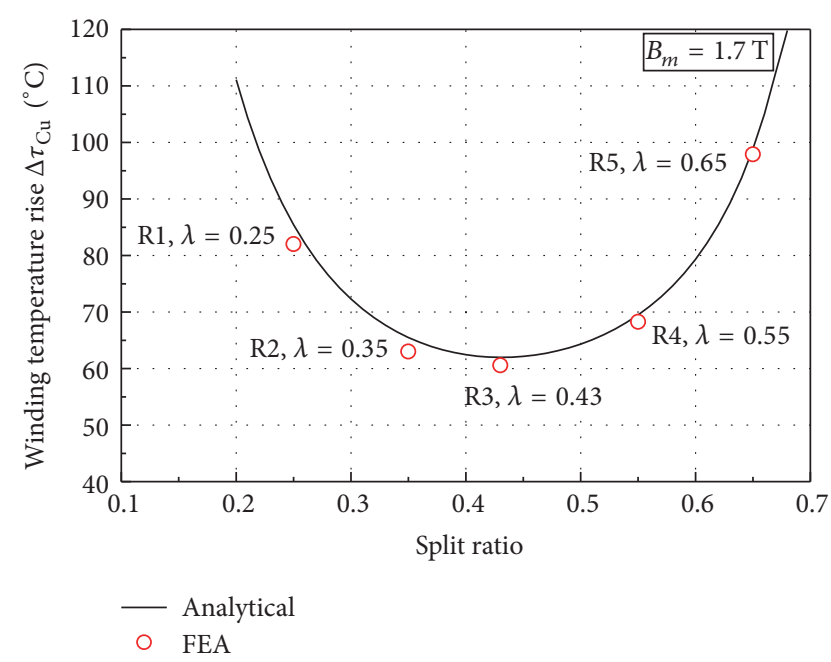

Figure 6: FEA verifications of designs R1, R2, R3, R4, and R5.

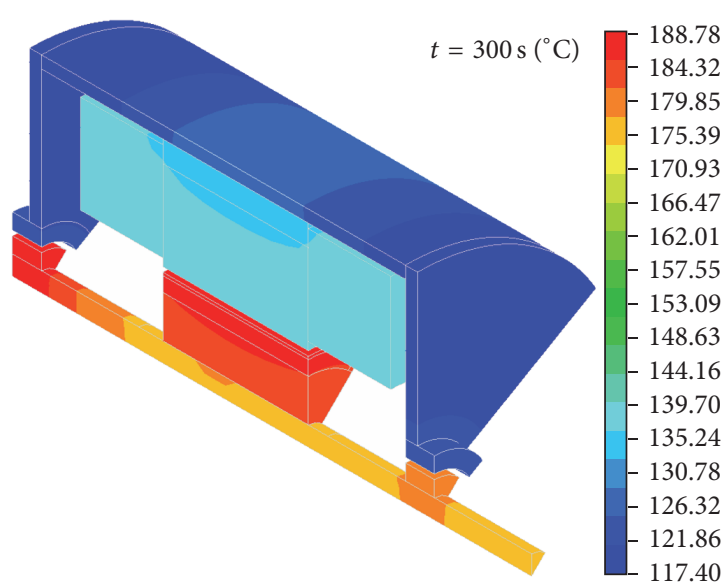

Figure 7: 3D thermal field of the design C4 (R3) at $t=300 \mathrm{~s}$. 


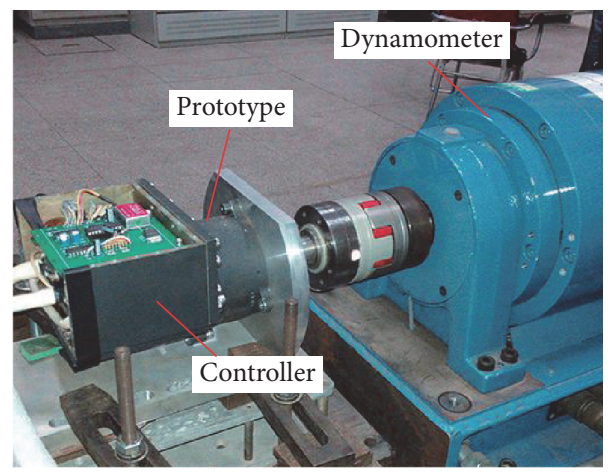

(a)

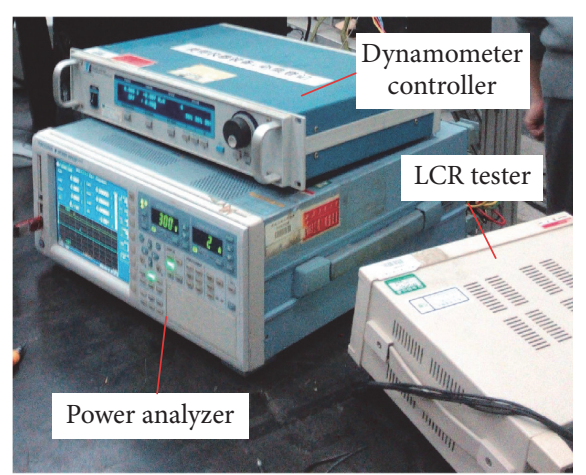

(b)

FIGURE 8: Prototype and measuring instruments. (a) Prototype, controller, and dynamometer. (b) Dynamometer controller, power analyzer, and LCR tester.

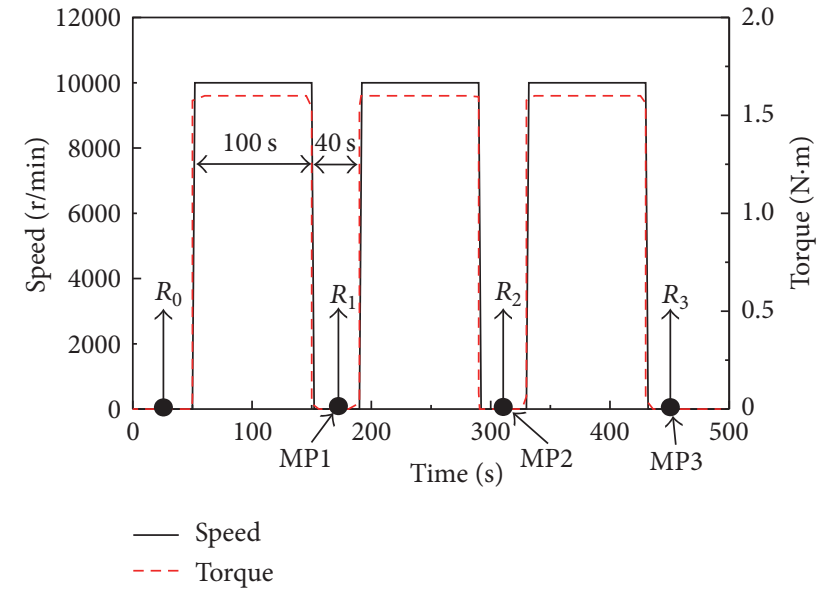

Figure 9: Process of the resistance measurement.

as $1.6 \mathrm{~N} \cdot \mathrm{m}$ and $10000 \mathrm{rpm}$, respectively. The load torque is adjusted by the dynamometer (Magtrol). The speed was controlled by adjusting the voltage of the DC power source while the same PWM duty ratio was kept as $100 \%$.

The winding temperature rise was measured by the resistance method [6]. The resistance values were measured by the LCR tester (HIOKI 3522-50). In order to measure the line resistance of the winding, the prototype was stopped for about $40 \mathrm{~s}$ after a $100 \mathrm{~s}$ running state. As shown in Figure 9, there are three resistance values $R_{1}, R_{2}$, and $R_{3}$ measured during the $40 \mathrm{~s}$ nonrunning state. The three measuring points are MP1, MP2, and MP3. Before the prototype runs, a line resistance value $R_{0}$ was measured when $\Delta \tau_{\mathrm{Cu}}=0$.

Using these measured resistances, the winding temperature rises are calculated by the following equation:

$$
\Delta \tau_{\mathrm{Cu} . i}=\frac{R_{i}-R_{0}}{\gamma_{\mathrm{Cu}} R_{0}},
$$

where $R_{i}$ represent $R_{1}, R_{2}$, and $R_{3} ; \Delta \tau_{\mathrm{Cu} . i}$ represent $\Delta \tau_{\mathrm{Cu} .1}$, $\Delta \tau_{\mathrm{Cu} .2}$, and $\Delta \tau_{\mathrm{Cu} .3}$, which are the winding temperature rise at MP1, MP2, and MP3, respectively.
TABLE 3: The analytical, FEA, and measured winding temperature rise of MP1, MP2, and MP3.

\begin{tabular}{lccc}
\hline Items & MP1 & MP2 & MP3 \\
\hline Analytical $\left({ }^{\circ} \mathrm{C}\right)$ & 21.4 & 42.0 & 61.9 \\
FEA $\left({ }^{\circ} \mathrm{C}\right)$ & 20.4 & 40.1 & 59.0 \\
Measured $\left({ }^{\circ} \mathrm{C}\right)$ & 22.7 & 40.8 & 57.4 \\
\hline
\end{tabular}

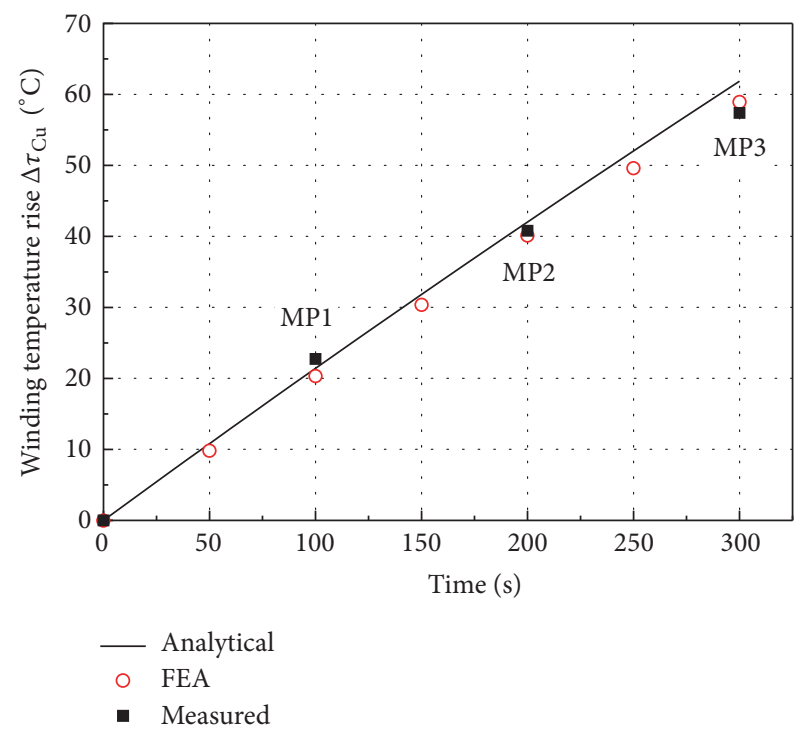

FIGURE 10: Experimental verification of the winding temperature rise.

The measured winding temperature rises, together with analytical and FEA winding temperature rise, are given in Table 3 and Figure 10. The errors between measured and analytical winding temperature rises at points MP1, MP2, and MP3 are 5.8\%, 3.0\%, and 7.8\%, respectively. The analytical result agrees well with the experimental result. The errors between measured and FEA results at points MP1, MP2, and MP3 are $10.5 \%, 1.6 \%$, and $2.7 \%$, respectively. The accuracy of the FEA simulation is also verified by experiments. Combining the FEA verification in Table 2, it can be proved 
that the optimal design is obtained accurately to minimize the winding temperature rise.

\section{Conclusion}

In order to improve the reliability of the short-time PMBLDCM in hypersonic vehicle, an electromagnetic-thermal integrated design optimization method is proposed. This method can satisfy both the requirements and constraints of thermal and electromagnetic design aspects. The method is based on electromagnetic analysis and thermal transient analysis. The electromagnetic and thermal design parameters are represented as functions of split ratio and $B_{m}$. The optimal design is determined after the optimal split ratio and $B_{m}$ are obtained. Since there are only two variables involved in the optimization, the analytical calculation of the optimization is highly simplified. The optimal design and the winding temperature rise are verified by the FEA and experiments. It can be proved that the optimal design is obtained accurately and the minimum winding temperature rise is achieved. The optimization method provides a fast and accurate solution for the electromagnetic-thermal integrated design of the shorttime duty PM-BLDCM.

\section{Competing Interests}

The authors declare that there are no competing interests.

\section{Acknowledgments}

This work was supported by the National Natural Science Foundation of China (Grant no. 51507143), Specialized Research Fund for the Doctoral Program of Higher Education of China (Grant no. 20136102120055), and the Industry Science and Technology Research Foundation of Shaanxi Province, China (Grant no. 2015GY090).

\section{References}

[1] J.-L. Wei and H. Chen, "Designing backstepping control system for hypersonic vehicle based on feedback linearization," International Journal of Aerospace Engineering, vol. 2015, Article ID 916328, 11 pages, 2015.

[2] D. E. Gildfind, R. G. Morgan, P. A. Jacobs, and M. Mcgilvray, "Production of high-mach-number scramjet flow conditions in an expansion tube," AIAA Journal, vol. 52, no. 1, pp. 162-177, 2014.

[3] X.-Y. Wu, J. Yang, H. Zhang, and C. Shen, "System design and analysis of hydrocarbon scramjet with regeneration cooling and expansion cycle," Journal of Thermal Science, vol. 24, no. 4, pp. 350-355, 2015.

[4] A. D. Cutler, G. Magnotti, L. Cantu, E. Gallo, R. Rockwell, and C. Goyne, "Dual-pump coherent anti-stokes raman spectroscopy measurements in a dual-mode scramjet," Journal of Propulsion \& Power, vol. 30, no. 3, pp. 539-549, 2014.

[5] W.-X. Fu, Y.-J. Wang, S.-P. Zhu, and Y.-Z. Xia, "Neural adaptive control of hypersonic aircraft with actuator fault using randomly assigned nodes," Neurocomputing, vol. 174, pp. 10701076, 2016.
[6] IEC 60034-1: 2010, "Rotating electrical machines-Part 1: Rating and performance," IEC, 2010.

[7] M. Villani, M. Tursini, G. Fabri, and L. Castellini, "High reliability permanent magnet brushless motor drive for aircraft application," IEEE Transactions on Industrial Electronics, vol. 59, no. 5, pp. 2073-2081, 2012.

[8] N. Jiao, W. Liu, T. Meng, J. Peng, and S. Mao, "Design and control of a two-phase brushless exciter for aircraft woundrotor synchronous starter/generator in the starting mode," IEEE Transactions on Power Electronics, vol. 31, no. 6, pp. 4452-4461, 2016.

[9] W.-P. Cao, B. C. Mecrow, G. J. Atkinson, J. W. Bennett, and D. J. Atkinson, "Overview of electric motor technologies used for more electric aircraft (MEA)," IEEE Transactions on Industrial Electronics, vol. 59, no. 9, pp. 3523-3531, 2012.

[10] M. A. Valenzuela, P. V. Verbakel, and J. A. Rooks, “Thermal evaluation for applying TEFC induction motors on short-time and intermittent duty cycles," IEEE Transactions on Industry Applications, vol. 39, no. 1, pp. 45-52, 2003.

[11] Q.-F. Lu, X.-M. Zhang, Y. Chen, X.-Y. Huang, Y.-Y. Ye, and Z. Q. Zhu, "Modeling and investigation of thermal characteristics of a water-cooled permanent-magnet linear motor," IEEE Transactions on Industry Applications, vol. 51, no. 3, pp. 2086-2096, 2015.

[12] A. Boglietti, E. Carpaneto, M. Cossale, and S. Vaschetto, "Statorwinding thermal models for short-time thermal transients: definition and validation," IEEE Transactions on Industrial Electronics, vol. 63, no. 5, pp. 2713-2721, 2016.

[13] K. N. Gyftakis, D. F. Kavanagh, M. Sumislawska, D. A. Howey, and M. McCulloch, "Dielectric characteristics of electric vehicle traction motor winding insulation under thermal ageing," in Proceedings of the 15th IEEE International Conference on Environment and Electrical Engineering (EEEIC '15), pp. 313-318, Rome, Italy, June 2015.

[14] M. Sumislawska, K. N. Gyftakis, D. F. Kavanagh, M. D. McCulloch, K. J. Burnham, and D. A. Howey, "The impact of thermal degradation on properties of electrical machine winding insulation material," IEEE Transactions on Industry Applications, vol. 52, no. 4, pp. 2951-2960, 2016.

[15] M. Galea, C. Gerada, T. Raminosoa, and P. Wheeler, "A thermal improvement technique for the phase windings of electrical machines," IEEE Transactions on Industry Applications, vol. 48, no. 1, pp. 79-87, 2012.

[16] D. Gerada, A. Mebarki, N. L. Brown, K. J. Bradley, and C. Gerada, "Design aspects of high-speed high-power-density laminated-rotor induction machines," IEEE Transactions on Industrial Electronics, vol. 58, no. 9, pp. 4039-4047, 2011.

[17] P. Zhang, G. Y. Sizov, M.-Y. Li et al., "Multi-objective tradeoffs in the design optimization of a brushless permanent-magnet machine with fractional-slot concentrated windings," IEEE Transactions on Industry Applications, vol. 50, no. 5, pp. 32853294, 2014.

[18] S. Dunkl, A. Muetze, and G. Schoener, "Design constraints of small single-phase permanent magnet brushless DC drives for fan applications," IEEE Transactions on Industry Applications, vol. 51, no. 4, pp. 3178-3186, 2015.

[19] Z. Kolondzovski, A. Arkkio, J. Larjola, and P. Sallinen, "Power limits of high-speed permanent-magnet electrical machines for compressor applications," IEEE Transactions on Energy Conversion, vol. 26, no. 1, pp. 73-82, 2011.

[20] X. Jannot, J.-C. Vannier, C. Marchand, M. Gabsi, J. Saint-Michel, and D. Sadarnac, "Multiphysic modeling of a high-speed 
interior permanent-magnet synchronous machine for a multiobjective optimal design," IEEE Transactions on Energy Conversion, vol. 26, no. 2, pp. 457-467, 2011.

[21] S. A. Semidey, Y. Duan, J. R. Mayor, R. G. Harley, and T. G. Habetler, "Optimal electromagnetic-thermo-mechanical integrated design candidate search and selection for surfacemount permanent-magnet machines considering load profiles," IEEE Transactions on Industry Applications, vol. 47, no. 6, pp. 2460-2468, 2011.

[22] D. Hanselman, Brushless Permanent Magnet Motor Design, Magna Physics Publishing, Oxford, UK, 2nd edition, 2006.

[23] W. Q. Chu, Z. Q. Zhu, and J. T. Chen, "Simplified analytical optimization and comparison of torque densities between electrically excited and permanent-magnet machines," IEEE Transactions on Industrial Electronics, vol. 61, no. 9, pp. 5000-5011, 2014.

[24] L. J. Wu, Z. Q. Zhu, J. T. Chen, Z. P. Xia, and G. W. Jewell, “Optimal split ratio in fractional-slot interior permanent-magnet machines with non-overlapping windings," IEEE Transactions on Magnetics, vol. 46, no. 5, pp. 1235-1242, 2010.

[25] Y. Shen and Z. Q. Zhu, "Analytical prediction of optimal split ratio for fractional-slot external rotor PM brushless machines," IEEE Transactions on Magnetics, vol. 47, no. 10, pp. 4187-4190, 2011.

[26] Y. Tang, Y. X. Xu, and J.-H. Hu, "Optimization of split ratio to design the PM brushless DC motor," in Proceedings of the International Conference on Electrical Machines and Systems (ICEMS '09), pp. 1-5, Tokyo, Japan, November 2009.

[27] T. Reichert, T. Nussbaumer, and J. W. Kolar, "Split ratio optimization for high-torque PM motors considering global and local thermal limitations," IEEE Transactions on Energy Conversion, vol. 28, no. 3, pp. 493-501, 2013.

[28] J. D. Ede, Z. Q. Zhu, and D. Howe, "Optimal split ratio for highspeed permanent magnet brushless DC motors," in Proceedings of the 5th International Conference on Electrical Machines and Systems (ICEMS '01), pp. 909-912, IEEE, Shenyang, China, August 2001.

[29] J.-X. Shen, P. Li, H. Hao, and G. Yang, "Study on electromagnetic losses in high-speed permanent magnet brushless machines-the state of the art," Proceedings of the CSEE, vol. 33, no. 3, pp. 62-74, 2013.

[30] Z.-Y. Huang, J.-C. Fang, X.-Q. Liu, and B.-C. Han, "Loss calculation and thermal analysis of rotors supported by active magnetic bearings for high-speed permanent-magnet electrical machines," IEEE Transactions on Industrial Electronics, vol. 63, no. 4, pp. 2027-2035, 2016.

[31] S. Jumayev, M. Merdzan, K. O. Boynov, J. J. H. Paulides, J. Pyrhönen, and E. A. Lomonova, "The effect of PWM on rotor eddy-current losses in high-speed permanent magnet machines," IEEE Transactions on Magnetics, vol. 51, no. 11, pp. 1-4, 2015.

[32] K. Atallah, D. Howe, P. H. Mellor, and D. A. Stone, "Rotor loss in permanent-magnet brushless AC machines," IEEE Transactions on Industry Applications, vol. 36, no. 6, pp. 1612-1618, 2000.

[33] H.-J. Guo, SKF Bearings General Catalogue, Shanghai Scientific and Technical Literature Press, 1991.

[34] J. Saari, Thermal analysis of high-speed induction machines [Ph.D. dissertation], Laboratory of Electromechanics, Helsinki University of Technology, Espoo, Finland, 1998. 


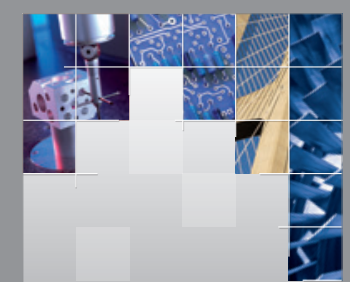

\section{Enfincering}
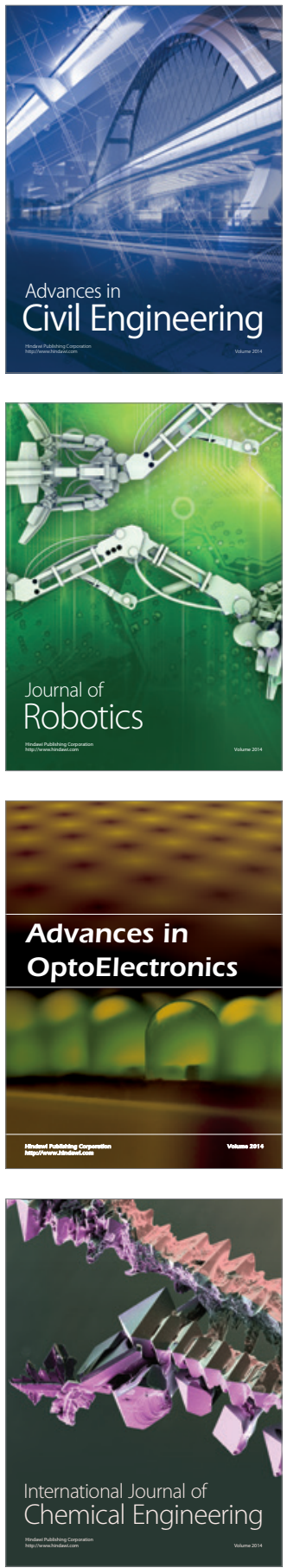

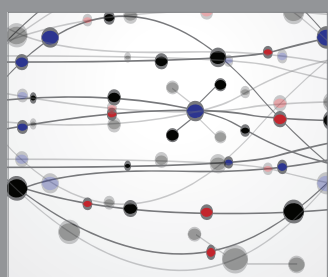

The Scientific World Journal

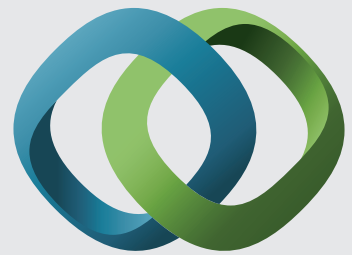

\section{Hindawi}

Submit your manuscripts at

http://www.hindawi.com
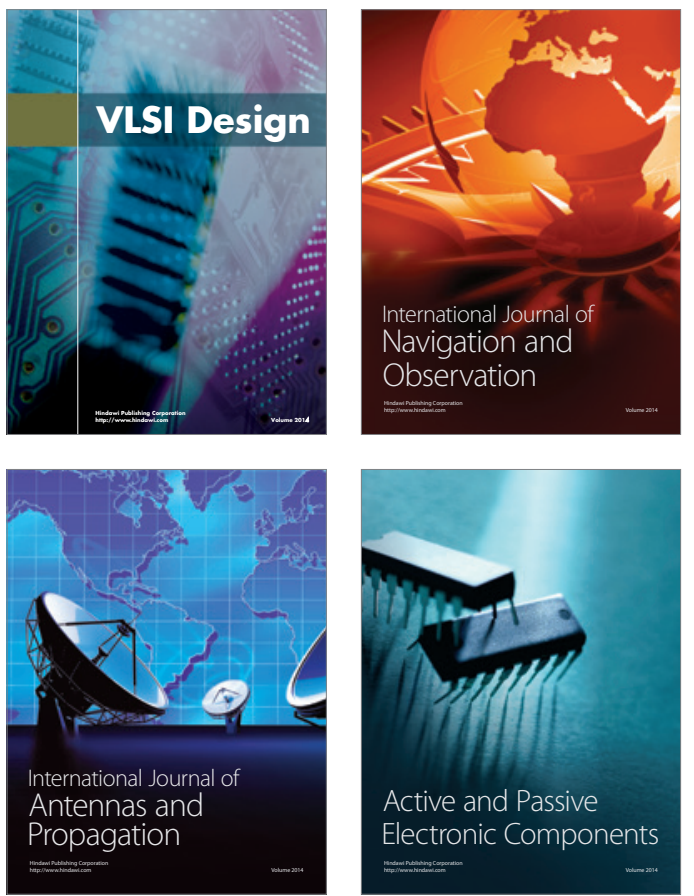
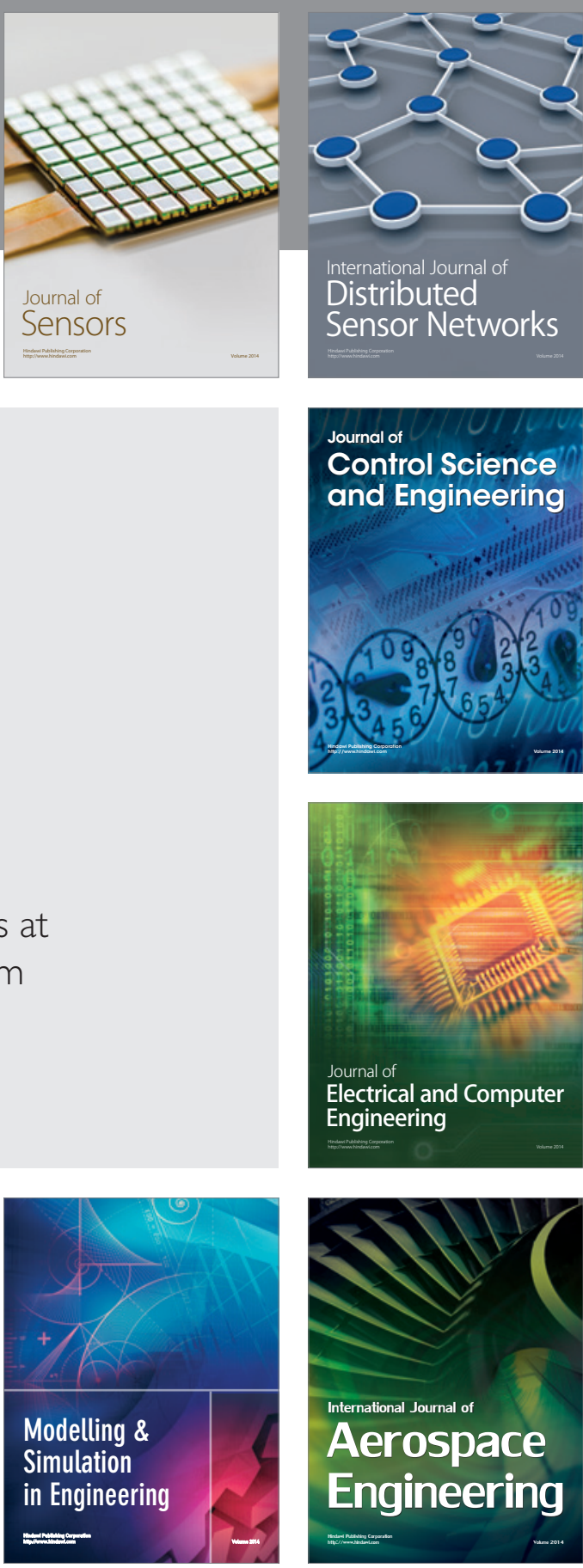

International Journal of

Distributed

Sensor Networks

Journal of

Control Science

and Engineering
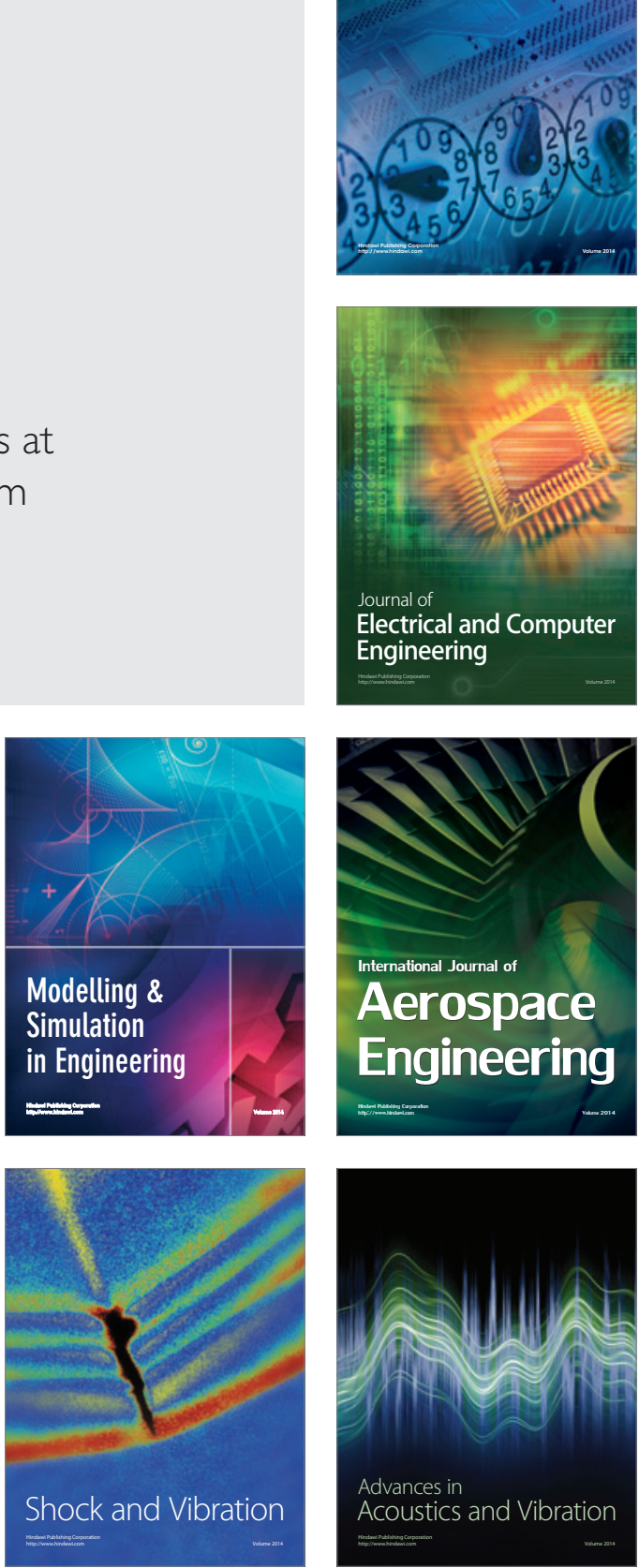